\title{
The attenuation of ECS-induced amnesia by reestablishing continuity with the training environment: A further examination*
}

\author{
C. J. MAH and D. J. ALBERT \\ University of British Columbia, Vancouver, Canada V6T 1W5
}

\begin{abstract}
Rats were given a footshock immediately following a step-through response in a one-trial passive avoidance task. An electronconvulsive shock (ECS) or a sham treatment was then administered 1 sec after the footshock. A retention test $24 \mathrm{~h}$ later showed that the ECS produced substantial amnesia. However, if the animals were allowed to recover for $15 \mathrm{~min}$ in the training apparatus immediately following the ECS instead of being returned to their home cages, the retention interference produced by the ECS was largely reversed. This reversal of ECS-induced amnesia was found to be time-dependent, as animals placed back into the apparatus after $15 \mathrm{~min}$ instead of immediately following the ECS did not show an attenuation of amnesia. When recovery from ECS was in the apparatus, the retention of avoidance response was still significantly less than that of control animals not given ECS. The results are interpreted in terms of a reactivation of consolidation by an interaction of short-term memory and the cues of the training environment.
\end{abstract}

Although the interference with retention by posttraining electroconvulsive shock (ECS) has frequently been interpreted as a disruption of the consolidation of learning (Glickman, 1961; McGaugh \& Herz, 1972; Mah \& Albert, 1973), the evidence concerning the mechanism of this disruption has remained very limited. Consequently, any new finding which bears upon this question merits close attention. One such finding is that rats left to recover from ECS in the training apparatus show an attenuation of amnesia. This result is important in that it points to a manipulation which can effectively reverse the disruptive effect of ECS. Azmitia, McEwen, and Quartermain (1972) have suggested that the reversal of the amnesia is due to establishing a continuity between the cues present during training and those present during recovery from ECS.

One question which arises from this reasoning is whether it is specifically recovery in the apparatus that is essential for the attenuation of amnesia. Azmitia et al appear to infer that it is, but they are not explicit. They also point out that Quartermain, McEwen, and Azmitia (1972) have found a recovery from amnesia with this task when the animals were given repeated retention tests. It could be concluded from this that not the place of recovery from ECS but the fact of having an exposure to the apparatus prior to test is critical. A second question has to do with the amount of memory recovered. Azmitia et al found no difference between animals receiving footshock only and those receiving footshock, ECS, and then allowed to recover in the apparatus, thus implying a total recovery from amnesia. But it may be that they were encountering a ceiling effect and that if additional test trials were given, it

*This research was supported by the National Research Council of Canada (APA 192) and the University Research Committee. The authors thank Steve Richmond for his comments on the manuscript. would have been found that the memory in the animals receiving ECS was still partially impaired.

The present experiment was designed to repeat the basic finding of Azmitia et al (1972) and to examine the two issues we have raised. We have examined the time dependence of the placement in the apparatus for the attenuation of amnesia and we have evaluated the strength of the learning remaining following recovery in the apparatus.

\section{METHOD}

\section{Animals}

The animals were 47 male, black-hooded rats $(250-350 \mathrm{~g})$ from the Canadian Breeding Farms and Laboratories. These animals were used in a previous experiment employing an approach task and had had no experience with electric shock.

\section{Surgery}

All animals had skull electrodes for administering ECS implanted bilaterally over the dorsolateral cortex 5 days before the experiment began. Electrode coordinates were $4 \mathrm{~mm}$ lateral to the midline and $1 \mathrm{~mm}$ posterior to bregma. The electrode consisted of a pin soldered onto the end of a stainless steel jeweller's screw (1 $\mathrm{mm}$ diam).

\section{Apparatus}

The passive avoidance apparatus was similar to that described by Azmitia et al (1972). It was a standard two-compartment box with a small startbox (17 cm long, $15 \mathrm{~cm}$ wide, and $33 \mathrm{~cm}$ high) opening into a larger compartment $(38 \mathrm{~cm}$ square and $44 \mathrm{~cm}$ high). A sliding door separated the two compartments, and the floor was composed of metal grids spaced $1.25 \mathrm{~cm}$ apart.

Footshock administered during passive avoidance training was controlled automatically. The shock was generated by a $60-\mathrm{Hz}$ $460-\mathrm{V}$ transformer in series with $85,000-\mathrm{ohm}$ resistance.

ECS was generated through a $60-\mathrm{Hz} 820-\mathrm{V}$ transformer connected in series to a $15,000-0 h m$ resistor. The effective current was $55 \mathrm{~mA}$ for $0.4 \mathrm{sec}$.

\section{Procedure}

The animals were given passive avoidance training 5 days after surgery. They were first placed into the startbox of the 
apparatus with wire leads for administering ECS clipped onto the skull electrodes. After $15 \mathrm{sec}$, the sliding door separating the two compartments of the apparatus was opened. When the animals had crossed into the larger chamber, the sliding door was closed and a footshock (0.3 sec duration) was automatically administered. Avoidance control animals $(\mathrm{FS}, \mathrm{N}=9$ ) were then removed from the apparatus and returned to their cages $1 \mathrm{sec}$ after the footshock.

The effect of recovery in the apparatus following ECS upon the amnesia induced by ECS was examined using two groups of animals. These animals were first given the passive avoidance training, and an ECS was then administered $1 \mathrm{sec}$ later to induce amnesia. Immediately following the ECS, one group (FS-ECS, $\mathrm{N}=10$ ) was removed from the apparatus and returned to home cages to recover from the ECS. These animals provided an estimate of the amnesic effect of ECS given $1 \mathrm{sec}$ after training. The other group (FS-ECS-App, $\mathrm{N}=14$ ) of animals was allowed to recover from the ECS in the large chamber of the apparatus for $15 \mathrm{~min}$ beginning immediately after the ECS to assess the effect of recovery in the apparatus upon the ECS-induced amnesia.

To determine whether the attenuation of amnesia produced by recovery in the apparatus was dependent on the time of exposure to the apparatus following ECS, a third group of animals was also given the footshock-ECS treatment. This group (FS-ECS-delApp, $\mathrm{N}=8$ ) was returned to home cages immediately after the ECS to remain there for $15 \mathrm{~min}$, at which time they were each placed into the large chamber of the apparatus for a $15-\mathrm{min}$ period.

A final group controlled for any aversive aftereffects of the FS-ECS treatment which might become conditioned to the cues of the training apparatus. The animals in this group (NCFS-ECS-App, $\mathrm{N}=6$ ) were given a noncontingent footshock in a black-walled chamber $(40 \times 40 \mathrm{~cm}$ and $40 \mathrm{~cm}$ high), followed $1 \mathrm{sec}$ later by ECS, and immediately placed into the training apparatus to recover for $15 \mathrm{~min}$.

After $15 \mathrm{~min}$, the physiological recovery from the ECS was evident in all the animals. The animals were typically exhibiting some movement around the apparatus by this time.

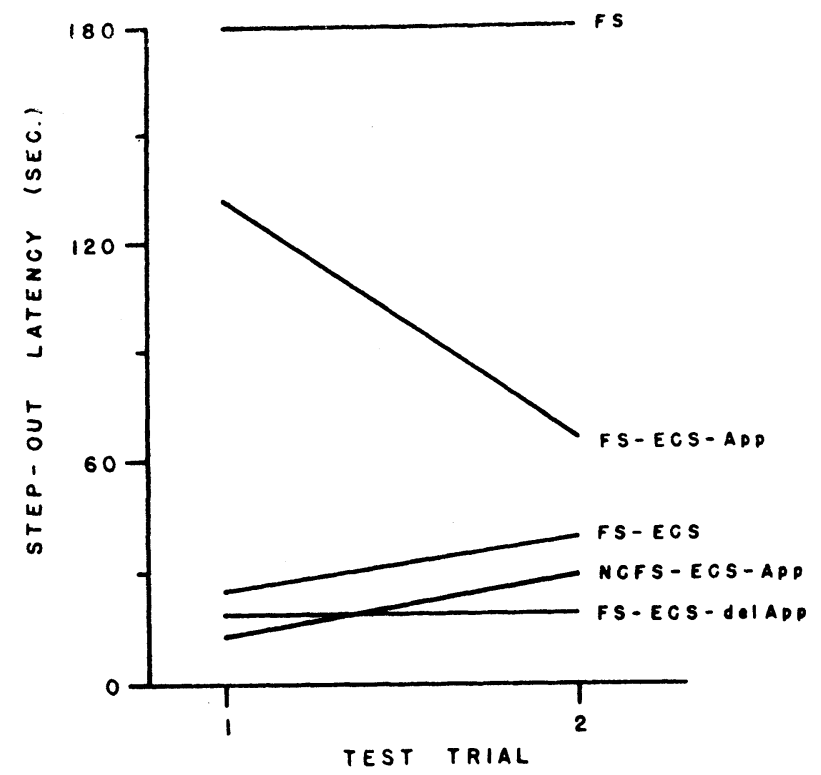

Fig. 1. Median step-out latency on Test Days 1 and 2. FS designates footshock; ECS, electronconvulsive shock given $1 \mathrm{sec}$ after the footshock; App, recovery from ECS in apparatus begins immediately following ECS; delApp, placement of animal into apparatus following ECS treatment begins $15 \mathrm{~min}$ after the ECS; NCFS-ECS, a footshock given outside of training apparatus followed by ECS $1 \mathrm{sec}$ later.
At 24 and $48 \mathrm{~h}$ after passive avoidance training, the animals were given a retention test. Each animal was placed into the startbox of the training apparatus; after $15 \mathrm{sec}$, the sliding door was retracted and the animal's latency to step out was recorded.

\section{RESULTS}

Median step-out latencies for each group on the first test trial are shown in Fig. 1. Animals which received the footshock upon stepping out and no other treatment (FS group) showed the maximum avoidance score (median $=180 \mathrm{sec}$ ). When ECS was given following the footshock (FS-ECS group) the avoidance level was significantly less $($ median $=25 \mathrm{sec} ; \mathrm{U}=9, \mathrm{p}<.02$; all comparisons between groups were with the Mann-Whitney U Test, two-tailed unless otherwise noted).

The critical experimental group was the one which was given footshock, ECS, and then allowed to recover in the apparatus for $15 \mathrm{~min}$ (FS-ECS-App). The median avoidance level of this group was $132 \mathrm{sec}$. This is a significantly longer step-out latency than that of the group which was given the identical FS-ECS treatment but which was allowed to recover from the ECS in its home cage (FS-ECS group; median latency $=25 \mathrm{sec}$, $\mathrm{U}=37, \mathrm{p}<.03$, one-tailed). However, it is also significantly less avoidance than that of animals given FS only $(U=25, p<.02)$.

The increased latency caused by allowing the animal to recover in the apparatus is time dependent. When the animals were allowed to recover in their home cages for the first 15 min following ECS and then put back into the apparatus for $15 \mathrm{~min}$ (Group FS-ECS-delApp), the step-out latency $($ median $=19 \mathrm{sec}$ ) was significantly less than that of the group allowed to recover in the apparatus for 15 min starting immediately following the ECS (Group FS-ECS-App; $\mathrm{U}=22.5, \mathrm{p}<.03$ ).

Recovery from ECS in the apparatus did not cause an increase in step-out latency independent of the avoidance training conditions. For animals receiving a noncontingent footshock outside the apparatus followed by ECS and then recovery in the apparatus (Group NCFS-ECS-App), the step-out latency (median = $13 \mathrm{sec}$ ) was not reliably different from animals (Group FS-ECS) given avoidance training, ECS, and then allowed to recover in the home cages $(U=16, p>.10)$.

The median avoidance levels on the second test day are shown in Fig. 1. On this day, the only significant difference is between the FS group and each of the other groups. The avoidance level of this group (FS, median latency $=66 \mathrm{sec}, \mathrm{U}=32.5, \mathrm{p}<.03$, one-tailed), as well as each of the other groups (all ps at least $<.02$ ). None of the other differences between groups are reliable.

\section{DISCUSSION}

Allowing the animal to recover in the training apparatus immediately following ECS significantly increases avoidance over animals given the same FS-ECS treatment but allowed to recover in their home cages. 
Control animals allowed to recover in the apparatus following a noncontingent footshock and ECS do not show this increased avoidance. Thus, the increase in avoidance with recovery from ECS in the apparatus following contingent footshock does not depend on fear-conditioning during the recovery process. The results confirm the previous demonstration of this phenomenon by Azmitia et al (1972).

Placing the animal back into the apparatus at $15 \mathrm{~min}$ instead of immediately following ECS produces no attenuation of amnesia. Apparently, the beneficial effect of reexposure to the apparatus is dependent on the presence of some process in the central nervous system which persists for only a short time following ECS. Further experiments will be needed to determine whether it is the presence of the training stimuli on awakening from the ECS per se or the presence of these cues at any time within some critical interval following the ECS that is important for the attenuation of amnesia.

The memory retained when recovery from ECS takes place in the apparatus is significantly weaker (as indicated by extinction of avoidance) than that retained by animals not given ECS. This result was found on both test trials and is unlike Azmitia's finding of no difference between animals given ECS and allowed to recover in the apparatus and control animals not given ECS. However, Azmitia et al were using stronger training conditions which produced avoidance at the cut-off level and only one test trial. Hence, differences between their groups may have been hidden by a ceiling effect.

In their original article describing the effect of recovery from ECS in the apparatus, Azmitia et al (1972) attributed the attenuation of amnesia to the establishment of an association between the memory surviving the ECS and other already existing memories. The new memory itself is not thought to be disturbed by ECS but without the association with other memories, which the reexposure to the apparatus allows, the memory of the avoidance learning cannot be expressed in behavior. Our results suggest that this formulation must be modified. In the first place, the recovered memory is incomplete and this conflicts with Azmitia et al's inference that the storage of the new memory is not disturbed by ECS. Second, reexposure to the training apparatus must happen within 15 min following ECS to produce the attenuation of amnesia. Thus, the effect of the reexposure appears to depend on the presence of a process which persists for only a short time following learning. In contrast, the explanation of Azmitia et al (1972) appears to allow the possibility that the attenuation of amnesia could occur regardless of when the animal is reexposed to the training apparatus.

These objections to Azmitia, McEwen, and Quartermain's hypothesis lead us to suggest an alternative based on short-term memory. Existing evidence suggests that a short-term memory can persist following ECS, but that it normally decays within minutes or hours (Geller \& Jarvik, 1968; McGaugh \& Landfield, 1970; Miller \& Springer, 1971). We suggest that if the animal is exposed to the training cues following ECS, activation of the short-term memory by the training cues would result in reactivation of the interrupted consolidation process. This would be akin to the rehearsal process in humans which is known to improve long-term retention (Kintsch, 1970).

\section{REFERENCES}

Azmitia, E. C., McEwen, B. S., \& Quartermain, D. Prevention of ECS-induced amnesia by reestablishing continuity with the training situation. Physiology \& Behavior, 1972, 8, 853-855. Geller, A., \& Jarvik, M. E. The time relations of ECS-induced amnesia. Psychonomic Science, 1968, 12, 169-170

Glickman, S. E. Perseverative neural processes and consolidation of the memory trace. Psychological Bulletin, 1961, 58, 218-233.

Kintsch, W. Learning, memory, and conceptual processes. New York: Wiley, 1970. Pp. 146-165.

McGaugh, J. L., \& Herz, M. J. Memory consolidation. San Francisco: Albion, 1972.

McGaugh, J. L., \& Landfield, P. Delayed development of amnesia following electroconvulsive shock. Physiology \& Behavior, 1970, 5, 1109-1114.

Mah, C. J., \& Albert, D. J. Electronconvulsive shock-induced retrograde amnesia: An analysis of the variation in the length of the amnesia gradient. Behavioral Biology, 1973, 9, 517-540.

Miller, R. R., \& Springer, A. D. Temporal course of amnesia in rats after electronconvulsive shock. Physiology \& Behavior, $1971,6,229-233$.

Quartermain, D., McEwen, B. S., \& Azmitia, E. C., Jr. Recovery of memory following amnesia in the rat and mouse. Journal of Comparative \& Physiological Psychology, 1972, 79, 360-370.

(Received for publication March 26, 1974; revision received May 9,1974 .) 